Article

\title{
Functionality and Storability of Cookies Fortified at the Industrial Scale with up to $75 \%$ of Apple Pomace Flour Produced by Dehydration
}

\author{
Snežana Zlatanović ${ }^{1, *(1)}$, Ana Kalušević ${ }^{2,3}$, Darko Micić $^{1}{ }^{(0)}$, Jovanka Laličić-Petronijević ${ }^{3}$, \\ Nikola Tomić ${ }^{3}{ }^{(0)}$, Sanja Ostojić ${ }^{1}$ and Stanislava Gorjanović ${ }^{1, *}$ \\ 1 Institute of General and Physical Chemistry, P.O. Box 45, 11158 Belgrade 118, Serbia; \\ micic83@gmail.com (D.M.); ostojicsanja404@gmail.com (S.O.) \\ 2 Institute of Meat Hygiene and Technology, Kaćanskog 13, 11000 Belgrade, Serbia; anakalusevic@gmail.com \\ 3 Faculty of Agriculture, University of Belgrade, P.O. Box 14, 11080 Belgrade, Serbia; \\ jovankal@agrif.bg.ac.rs (J.L.-P.); tsnikola@agrif.bg.ac.rs (N.T.) \\ * Correspondence: snezana.zlatanovic@gmail.com (S.Z.); stasago@yahoo.co.uk (S.G.); \\ Tel.: +381-11-2182389 (S.Z.); +381-61-243-9803 (S.G.)
}

Received: 23 October 2019; Accepted: 5 November 2019; Published: 8 November 2019

\begin{abstract}
Apple pomace flour (APF) with high content of dietary fibers (DF), total polyphenolics (TPCs) and flavonoids (TFCs) was produced at the industrial scale. Bulk and tapped density, swelling, water and oil holding capacity, solubility and hydration density of fine and coarse APF with average particle size 0.16 and $0.50 \mathrm{~mm}$ were compared. The effect of wheat flour substitution with $25 \%, 50 \%$ and $75 \%$ of fine and coarse APF was studied upon cookies production at the industrial scale and after one year of storage. Coarse APF performed better in respect to sensorial properties, content and retention of dietary compounds and antioxidant $(\mathrm{AO})$ activity. The cookies with optimal share of coarse APF (50\%) contained $21 \mathrm{~g} / 100 \mathrm{~g}$ of DF and several times higher TPC, TFC as well as AO activity than control cookies, retained well health promoting compounds and maintained an intensely fruity aroma and crispy texture. They were acceptable for consumers according to the hedonic test.
\end{abstract}

Keywords: antioxidant; apple pomace; dietary fiber; cookies; gluten free; polyphenolics

\section{Introduction}

Apple (Malus sp.) is the most processed fruit that generates a high amount of apple pomace (AP) composed of peel, pulp, stems and seeds. The composition, health benefits and safety of AP were analyzed comprehensively [1]. It is high in dietary fibers (DF; soluble pectins, $\beta$-glucans, galactomanan gums and insoluble lignin, cellulose and hemicelluloses) [2,3] with antioxidant (AO), antitumor and hepatoprotective activities [4,5]. AP also represents a rich source of polyphenolic compounds (catechins, procyanidins, phloridzin, phloretin glycosides, caffeic and chlorogenic acid, quercetin and cyanidin glycosides) with antioxidative, antiproliferative, anti-inflammatory, antidiabetic and cardioprotective effects [6-9]. AP's huge potential for conversion into edible products with additional nutritional value and flavor was demonstrated [10] but not fully exploited. Commercially available food items with declared AP in their composition are still rare.

To obtain a non-perishable food ingredient, the high water content in AP (approx. 75\%) needs to be reduced. The removal of water without affecting nutritional and functional properties represents a major obstacle to commercial use of AP. Various drying techniques to reduce moisture in AP have been tested. Among them, time- and energy-consuming freeze drying retains the highest level of bioactive compounds [11-14]. Recently, an efficient low-cost drying method was developed to dehydrate AP at industrial scale. The time required to reduce moisture, as well as energy consumption, was much lower 
than in freeze drying [15]. Dehydrated AP was ground and apple pomace flour (APF), with high DF, polyphenolics and flavonoids content, distinct antioxidant (AO) activity, antidiabetic and antilipemic effect was produced [16]. High temperature of glass transition and low activity of water indicate stability throughout the shelf life, while thermal stability up to $220^{\circ} \mathrm{C}$ confirms APF applicability as an ingredient in bakery and confectionery products [17].

Due to the increasing incidence of various metabolic disorders, obesity and gluten intolerance, there is an interest in developing fortified products with a high content of DF and AOs, reduced content of gluten and pleasant flavor. As ready-to-eat, quite durable products with long shelf life, cookies are very popular snacks. In addition, they represent a matrix suitable for fortification, thus providing an opportunity for the intake of important nutrients. While there are many studies of AP-enriched cookies, they still are not standard products. Most studies examining the effect of AP supplementation on the quality of biscuits were conducted at the laboratory level, using AP produced and/or dried in laboratory conditions. The majority of studies also reported supplementation, which does not exceed $30 \%$ of ordinary flour $[2,10,18,19]$. Based on sensory evaluation, cakes, bread and biscuits can be enriched with $5 \%, 10 \%$ and $15 \%$ of AP, respectively [20]. According to Jung et al. [21], cookies fortified with up to $20 \%$ AP had a pleasant fruit aroma and were found to be softer, chewier and damper than the control. Addition of AP in brown rice flour up to $10 \%$ did not cause significant change in overall acceptability of gluten-free crackers [22]. The study conducted by Kaushal and Joshi showed that as much as $30 \%$ AP powder could be incorporated in preparation of good quality cookies [23]. According to Saeed et al. [24], all sensory parameters decreased in cookies with $40 \%$ of AP. Oatmeal cookies made with $30 \%, 40 \%$ and $50 \%$ of AP were characterized as moderately acceptable [25].

This study deals with apple pomace flour produced by applying recently developed dehydration technology, and cookies obtained there of APF, both produced at the industrial scale level. Technological characteristics of fine and coarse APF, and degree of fortification of cookies made with $25 \%, 50 \%$ and $75 \%$ of APF were determined. Optimal share and preferred granulation of APF in respect to cookies formulation was established based on the increase of DF, total polyphenolics (TPCs), flavonoids (TFCs) and $\mathrm{AO}$ activity and sensorial properties investigated by an experts panel employing the scoring method, as well as the preservation of both functional and sensorial properties upon a common period of storage (a year). In addition, cookies with the optimal share of APF of preferred granulation as chosen by the sensory panel were tested using the hedonic test. Generally, the main purpose of research was conducted through determination of dietary compounds content and technological properties of industrially produced APF. This study represents a step towards fortifying popular types of cookies that lack dietary fibers and AOs at the industrial scale, by replacing a significant portion of wheat flour with APF, without compromising cookies acceptability, thus providing reliable insight in fortified cookies functionality and storability.

\section{Materials and Methods}

\subsection{Materials}

\subsubsection{Chemicals}

Gallic acid, Folin-Ciocalteu's reagent, hydrochloric acid, sodium acetate trihydrate, glacial acetic acid, aluminum chloride, sodium nitrate, sodium carbonate (anhydrous) and Celite *545 AW (Merck (Darmstadt, Germany), 2,2-diphenyl-1-picrylhydrazyl (DPPH), 2,2'-azinobis-3ethylbenzothiazoline-6-sulfonic acid (ABTS), 6-hydroxy-2,5,7,8-tetramethylchroman-2-carboxylic acid (Trolox) and quercetin (Sigma-Aldrich, Steinheim, Germany), sodium hydroxide (Fisher Scientific, Loughborough, UK), sodium dihydrogen phosphate, disodium hydrogen phosphate and sodium acetate (Centrohem, Belgrade, Serbia), ethanol (Vrenje Spiritana, Belgrade, Serbia), acetone (J.T. Baker Chemical Co., Phillipsburg, NJ, USA) and Megazyme kit (Megazyme, Chicago, IL, USA) were used. All chemicals were of analytical grade. 


\subsubsection{Apple Pomace Flour Production and Analysis}

Whole apple pomace (AP) containing pulp, peel, seeds and stems, originated from mixed varieties of apples, with idared prevalent, grown conventionally in Serbian orchards in 2017, collected from the juice factory Fruvita (Smederovo, Serbia) immediately after pressing, was dehydrated at the industrial level for $5 \mathrm{~h}$ below $55{ }^{\circ} \mathrm{C}$ using "Solaris" dehydrator (Drayer ltd., Belgrade Serbia) [15]. Dried AP was ground into fine and coarse flour, packed in multilayer paper bags and kept in common storage conditions before analysis and application in confectionery. Water activity $\left(a_{w}\right)$ was determined by $a_{w}$ meter Testo 650 (Testo AG, D-79853, Lenzkirch, Germany). Content of DF in APF was determined as described in Section 2.4.1. APF was extracted by occasional shaking with 1:1 mixture of ethanol and water $(1400 \mu \mathrm{L})$ at room temperature during $60 \mathrm{~min}$. Supernatant obtained by centrifugation at 12,000 rpm (Centrifuge MiniSpinßplus, Eppendorf, AG, Hamburg, Germany) for 10 min was tested for TPC, TFC and radical scavenging activity towards DPPH and ABTS radicals as described in Sections 2.4.2 and 2.4.3.

\subsection{Determination of Technological Properties of APF}

Particle size analysis-particle size was determined by dry sieving after grinding. The particle size distribution of fine and coarse APF was determined by sieving $100 \mathrm{~g}$ of flour on a set of sieves with pore sizes of 1000, 500, 300, 160, 125, 90, 63 and $45 \mu \mathrm{m}$. The remaining mass on top of each sieve was weighed and used to calculate particle size distribution [26].

Bulk and packed density—a $50 \mathrm{~mL}$ graduated cylinder was filled with $10.0 \mathrm{~g}$ of fine or coarse APF. APF volumes were recorded for the level reached after gentle tapping (bulk density) or after applying pressure manually to achieve a maximal reduction of the volume (packed density). Results are expressed as weight per volume of $\mathrm{APF}(\mathrm{g} / \mathrm{L})[27]$.

Water holding capacity (WHC) - APF samples of different particle size (fine and coarse; $1.0 \mathrm{~g}$ ) were dissolved in distilled water $(30 \mathrm{~mL})$. The suspension of APF in distilled water $(30 \mathrm{~mL})$ was left for $24 \mathrm{~h}$ at room temperature. After centrifugation at $3600 \mathrm{rpm}$ for $20 \mathrm{~min}$, aqueous supernatant was removed and the residue was measured. Results are expressed as weight of water bound per gram of $\operatorname{APF}(\mathrm{g} / \mathrm{g})[28]$.

Solubility-the aqueous supernatant that was removed after centrifugation during WHC determination was dried in the air oven at $105^{\circ} \mathrm{C}$ until constant weight for subsequent analysis of solubility pattern. Water solubility index was determined from the quantity of dry solids obtained after drying the supernatant and is expressed as a percentage (\%).

Hydrated density (HD)_APF (1.0 g) was added to a graduated cylinder filled with distilled water $(10 \mathrm{~mL})$ carefully, avoiding adhesion of particles to the cylinder walls. The difference between volume of water before and after APF addition was recorded after $15 \mathrm{~min}$. Results are expressed as weight of APF (g) per water displaced (mL) [28].

Swelling capacity (SWC) - APF (1.0 g) was loaded into a graduated tube and $30.0 \mathrm{~mL}$ of water were added. After $18 \mathrm{~h}$ of equilibration, the bed volume was recorded. Results are expressed as volume occupied by APF (mL) per original APF weight $(\mathrm{g})$ [29].

Oil holding capacity $(\mathrm{OHC})$ - the mixture of APF $(1.0 \mathrm{~g})$ and $10.0 \mathrm{~mL}$ sunflower oil was kept for $24 \mathrm{~h}$ at room temperature without disturbance. After centrifugation at $3600 \mathrm{rpm}$ for $25 \mathrm{~min}$, supernatant was removed and weight of the residue measured. Results are expressed as gram of oil retained per gram of sample [27].

\subsection{Production of Fortified Cookies with $25 \%, 50 \%$ and $75 \%$ of APF}

Standard cookie dough (control) was prepared according to a traditional method. Ingredients acquired from the local suppliers (white wheat flour $59 \%$, palm fat $19 \%$, powdered sugar $14 \%$, invert sugar $4 \%$, salt $2 \%$ and baking powder $2 \%$ ) were mixed in a single phase procedure. Fortified cookies were produced by replacing $25 \%, 50 \%$ and $75 \%$ of wheat flour with fine (F) and coarse (C) APF. They 
were marked as CF25, CF50, CF75 (CF-cookies with fine flour), CC25, CC50 and CC75 (CC-cookies with coarse flour). After passing through a two roll dough feed unit, cookies with a $40 \mathrm{~mm}$ diameter and 5-6 mm thickness were formed using a wire cut machine (Polin, Multidrop, Italy) and baked in an industrial electric deck oven at $175^{\circ} \mathrm{C}$ for $10 \mathrm{~min}$. Immediately after cooling cookies were packed in duplex polypropylene (PP) bags designed for food storage (BLIKPRODUKT" ltd. Kikinda, Serbia), closed and stored at ambient temperature.

\subsection{Determination of Fortified Cookies Functionality}

\subsubsection{Determination of Dietary Fiber Content}

Content of dietary fibers was determined in the APF and cookies of coarse flour, according to the AOAC met.985.29-enzymatic gravimetric method [30].

\subsubsection{Determination of Total Polyphenolics (TPCs) and Flavonoids Content (TFCs)}

Finely ground cookies (100 mg) were extracted by occasional shaking with 1:1 mixture of ethanol and water $(1400 \mu \mathrm{L})$ at room temperature during $60 \mathrm{~min}$. Supernatant was obtained by centrifugation at 12,000 rpm for $10 \mathrm{~min}$. TPC, TFC and AO activity (DPPH and ABTS) of extracts was determined immediately after extraction.

TPC of extracts was determined according to the procedure reported by Singleton and Rossi [31]. An aliquot of diluted extracts $(0.25 \mathrm{~mL})$ was mixed with Folin-Ciocalteu's phenol reagent at 10-fold dilution $(1.25 \mathrm{~mL})$ and allowed to react for $6 \mathrm{~min}$. Sodium carbonate solution $(75 \mathrm{~g} / \mathrm{L}, 1 \mathrm{~mL})$ was added, and the mixture and shaken. After reacting for $2 \mathrm{~h}$ at room temperature in dark, absorbance was measured at $765 \mathrm{~nm}$. The results are expressed as mg of gallic acid equivalents per gram of sample, $\mathrm{mg}(\mathrm{GAE}) / \mathrm{g}$.

TFC of extracts was determined according to the procedure reported by Zhishen et al. [32]. An aliquot of extracts $(2.5 \mathrm{~mL})$ was mixed with $150 \mu \mathrm{L}$ of a $5 \% \mathrm{NaNO}_{2}$ solution and allowed to react for $6 \mathrm{~min} .10 \% \mathrm{AlCl}_{3}(150 \mu \mathrm{L})$ was added and the mixture was left to react for $5 \mathrm{~min}$. Afterwards, $1 \mathrm{~mL}$ of $1 \mathrm{~mol} / \mathrm{L} \mathrm{NaOH}$ solution and $1.2 \mathrm{~mL}$ of distilled water were added and absorbance was measured at $510 \mathrm{~nm}$. The results were expressed as $\mathrm{mg}$ of quercetin equivalents per gram of sample $(\mathrm{QE}) / \mathrm{g}$.

\subsubsection{Determination of Antioxidant Activity}

The DPPH scavenging ability of extracts was determined according to a slight modification of the procedure reported by Kaneda et al. [33]. An aliquot of the diluted sample $(0.2 \mathrm{~mL})$ was mixed with $2.8 \mathrm{~mL}$ of DPPH solution (mixture of $1.86 \times 10^{-4} \mathrm{~mol} \mathrm{~L}^{-1} \mathrm{DPPH}$ in ethanol and $0.1 \mathrm{M}$ acetate buffer $(\mathrm{pH}=4.3)$ in volume ratio $2: 1(v / v))$. Free radical scavenging activity was determined by measuring the absorbance of the solution at $525 \mathrm{~nm}$ after $40 \mathrm{~min}$ of reaction at room temperature in the dark.

The ABTS scavenging ability of extracts was determined by the procedure reported by Re et al. [34]. By the reaction between $7 \mathrm{mM}$ water solution of ABTS and $2.45 \mathrm{mM}$ potassium persulfate (1:1), ABTS ${ }^{+}$ cation radical was produced. The obtained solution was stored in the dark at room temperature for 12-16 h before use. Thirty $\mu \mathrm{L}$ of each diluted sample was mixed with $3.0 \mathrm{~mL}$ of ABTS solution. After reacting for $6 \mathrm{~min}$, absorbance at $734 \mathrm{~nm}$ was read. The results are expressed as mmol of Trolox equivalents per gram of sample ( $\mathrm{mmol} \mathrm{TE} / \mathrm{g})$.

\subsection{Sensory Analysis of Fortified Cookies using a Scoring Method}

Sensory quality rating was conducted in a laboratory for sensory evaluation in two testing periods: within two weeks after production $(0 \mathrm{~m})$ and after one year $(12 \mathrm{~m})$ of storage. The overall sensory quality was determined using the scoring method $(0-5)$ whereby the representative sensory properties were evaluated: appearance (color, surface, size and shape), texture (structure, snap, doneness and chewiness) and flavor (odor and taste). Eight trained evaluators were engaged in the panel and pre-trained in two sessions. Multiplying the scores assigned by the panel-by the corresponding 
coefficients of importance (so called "weighted coefficient"), the weighted mean value of the scores was obtained as an expression of the final quality of the product. Quality categories were determined depending on score ranges: $<2.5$ - does not meet the quality requirements; $2.5-3.5$-good quality, 3.5-4.5-very good quality and 4.5-5.0—excellent quality.

\subsection{Estimation of Fortified Cookies Storability}

Having spent 12 months packed in plastic bags, stored in a cool and dark place at ambient temperature, the cookies were analyzed in the same way as described in Section 2.4. and Section 2.5.

\subsection{Estimation of Optimal Share and Particle Size of APF}

Principal components analysis (PCA) was conducted and changes in functional and sensorial properties during storage were considered in evaluation of optimal percentage of APF ratio and particle size.

\subsection{Estimation of Consumer Acceptance of Fortified Cookies with Optimal APF Share}

In accordance with the results of sensory quality judging, for the purpose of acceptance testing, a cookie sample containing 50\% of coarse granulation APF was prepared. Consumer testing was performed by 115 students from the University of Belgrade. The chosen sample was evaluated for 'overall acceptance', 'texture acceptance', 'flavor acceptance' and 'odor acceptance' using the 9-point hedonic scale ( $1=$ dislike extremely, $5=$ neither like nor dislike and $9=$ like extremely), and also, using 9-points just-about-right (JAR) scales ( $1=$ too little, $5=$ JAR and $9=$ too much) for intensity of 'color' (too light/pale-JAR-too dark), 'sweetness' (not sweet enough-JAR-too sweet), 'apple aroma' (too weak-JAR-too strong), 'crispiness' (not crispy enough-JAR-too crispy), 'doneness' (underdone-JAR-overdone) and 'chewiness' (too easy to chew-JAR-too hard to chew).

\subsection{Statistical Analysis}

All experiments were performed in triplicate and the obtained results are expressed as mean \pm standard deviation (SD). Data were subjected to analysis of variance (ANOVA) for comparison of means, and significant differences between groups were calculated according to Tukey's HSD (honestly significant difference) test $(p<0.05)$. In order to determine the degree of change in antioxidative and sensory characteristics of the samples during the 12-month period, the PCA, followed by a Varimax rotation was performed. Statistical analyses were performed with XLSTAT (version 2014.5.03, Addinsoft, New York, NY, USA), analysis and statistics add-in for MS Excel.

Consumer acceptance data were subjected to mean drop analysis as described by Schraidt [35]. JAR scores were grouped into three categories: 'below JAR' (the scores 1, 2 and 3); 'at JAR' (4, 5 and 6) and 'above JAR' (7, 8 and 9). Mean drops were calculated by subtracting the mean overall hedonic score of each non-JAR category from the mean of the JAR category. The JAR-categories overall hedonic means were compared by ANOVA and Tukey's HSD test. Minimum percentage skew for 'Not Just Right' (the cut-off) was set at $20 \%$ of the total consumer panel.

\section{Results and Discussion}

\subsection{Production and Analysis of APF}

All-natural gluten-free apple pomace flour (APF) without preservatives, artificial colors, dyes or any additives was produced within the scope of this study at industrial scale from whole apple pomace (AP; peel, pulp, stems and seeds), by dehydration followed by grinding to the desired particle size as disclosed [16]. It possesses low $\mathrm{a}_{\mathrm{w}}(0.22)$, high DF content $(42 \%)$, TPC (7.0 $\left.\pm 0.4 \mathrm{mg} \mathrm{GAE} / \mathrm{g}\right)$ and TFC $(25.0 \pm 1.5 \mathrm{mg}$ QE/g) and prominent scavenging activity against DPPH and ABTS radical $(9.4 \pm 0.9$ and $4.3 \pm 0.3 \mathrm{mmol}$ TE $100 / \mathrm{g})$. 


\subsection{Technological Properties of Industrially Produced APF}

Technological properties of fine and coarse APF were assessed (Table 1). Since APF was produced with the intention to be used in bakery and confectionery products, some of the parameters determined were compared with literature data available for wheat flour as well as commonly used gluten-free flours.

Table 1. Technological properties of coarse and fine apple pomace flour (APF).

\begin{tabular}{ccc}
\hline Technological Properties & APF (Fine) & APF (Coarse) \\
\hline Bulked density (g/L) & $435 \pm 16$ & $459 \pm 20$ \\
Packed density $(\mathrm{g} / \mathrm{L})$ & $632 \pm 25$ & $591 \pm 24$ \\
Water holding capacity $(\mathrm{g} / \mathrm{g})$ & $4.69 \pm 0.19$ & $4.79 \pm 0.18$ \\
Solubility $(\%)$ & $27.9 \pm 0.9$ & $29.1 \pm 0.7$ \\
Hydrated density $(\mathrm{g} / \mathrm{mL})$ & $0.50 \pm 0.02$ & $0.63 \pm 0.03$ \\
Swelling capacity $(\mathrm{mL} / \mathrm{g})$ & $5.5 \pm 0.2$ & $7.0 \pm 0.3$ \\
Oil holding capacity $(\mathrm{g} / \mathrm{g})$ & $1.27 \pm 0.04$ & $1.4 \pm 0.05$ \\
\hline
\end{tabular}

Average particle size of 0.16 and $0.5 \mathrm{~mm}$ for fine and coarse APF was determined by sieving, in the intervals of 0.06 to 0.30 and 0.06 to $1 \mathrm{~mm}$, respectively. The maximum weight percentage for coarse flour is between $500 \mu \mathrm{m}<n<1 \mathrm{~mm}(28.32 \%)$, while for fine flour the distribution is slightly different and the maximum weight percentage is $27.78 \%$ for particle size between $160 \mu \mathrm{m}<n<300 \mu \mathrm{m}$.

Bulk density of fine and coarse APF was $435 \pm 16$ and $459 \pm 20 \mathrm{~g} / \mathrm{L}$, and packed density $632 \pm 25$ and $591 \pm 24 \mathrm{~g} / \mathrm{L}$, respectively. Bulk and packed density of sugar-depleted AP powder dominantly consisting of particles smaller than $150 \mu \mathrm{m}$ was 557 and $447 \mathrm{~g} / \mathrm{L}$ respectively [36]. Lowering of moisture content decreased the bulk density of apple powders obtained using various drying methods. The same trend was observed for tapped density of AP that ranged from 430 to $580 \mathrm{~g} / \mathrm{L}$ [37]. Based on data available for other flours, it can be seen that while packed density values of APF are in concordance to those found in wheat flour $(640 \mathrm{~g} / \mathrm{L})$ [38], bulk density is lower compared to other flours including wheat [39,40], rice [41] and corn [42]. According to Oladapo et al. [43], low values of bulk densities make the flour more suitable for the baking process.

Water holding capacity, referring to the ability of material to bind and hold water within the matrix, depends on the content and chemical structure of DF [44]. Reported AP WHC ranged from $1.62 \mathrm{~g} / \mathrm{g}$ [45] to $6.34 \mathrm{~g} / \mathrm{g}$ [46]. Values obtained for WHC of fine and coarse APF $(4.69 \pm 0.19$ and $4.79 \pm 0.18 \mathrm{~g} / \mathrm{g})$ were in concordance with previously reported data $[36,47,48]$. The main factors affecting WHC are related to the composition of AP, possible pre-treatment such as washing or bleaching, and drying conditions. Breakdown of cell wall polysaccharides does not occur at low dehydration temperatures, allowing for a high WHC of APF.

Since the amount of water needed to hydrate flour components to produce dough with optimum consistency is one of the most fundamental quality parameters of flour [49], values obtained for APF were compared with reported data for both wheat and other flours. The WHC values obtained for APF were found higher than those reported for fine $(1.14 \mathrm{~g} / \mathrm{g})$ [50], full fat $(1.85 \mathrm{~g} / \mathrm{g})$ and defatted $(1.92 \mathrm{~g} / \mathrm{g})$ wheat flour [39], as well as commercial $(0.88 \mathrm{~g} / \mathrm{g})$ [41], full fat $(1.26 \mathrm{~g} / \mathrm{g})$ and defatted $(1.56 \mathrm{~g} / \mathrm{g})$ rice [39] and corn flour (1.57 g/g) [51]. WHC of APF was also found higher than the WHC reported for oat bran $(2.1 \mathrm{~g} / \mathrm{g})$ [52]. It is known that flours with a high WHC are widely used in foods like meat products, custards and soups to enhance thickening and viscosity, and in baked products to improve freshness and handling characteristics [10].

The ability of a powder to dissolve in water indicates its capacity of rehydration. Solubility affects the functional characteristics of powders in food systems. Lower values for fine and coarse APF solubility $(27.9 \% \pm 0.9 \%$ and $29.1 \% \pm 0.7 \%)$ corresponded to high content of DF. Apple pomace powder solubility of $37.5 \%$ (total fiber content $26.5 \%$ ) obtained by flash blanching, freeze-drying was reported [53]. 
High hydrated density of fine and coarse APF $(0.50 \pm 0.02$ and $0.63 \pm 0.03 \mathrm{~g} / \mathrm{mL})$ in comparison to reported data [28] can also be attributed to conditions of water removal that did not cause cell wall material shrinkage.

Swelling capacity, as well as WHC and $\mathrm{OHC}$, provide insight regarding DF behavior during food processing and gut transit [54]. SWC, referred to the amount of insoluble fiber, was $5.5 \pm 0.2$ and $7.0 \pm 0.3 \mathrm{~mL} / \mathrm{g}$ for fine and coarse APF, respectively. SWC of sugar-depleted AP powder was found to be $7.0 \mathrm{~mL} / \mathrm{g}$ [55]. Porous structures developed within the cell wall matrix during the process of water removal at low temperature allow for easy and complete rehydration.

Oil holding capacity of $1.27 \pm 0.04$ and $1.40 \pm 0.05 \mathrm{~g} / \mathrm{g}$ ascribed to fine and coarse APF, respectively, are in accordance with values reported for laboratory produced AP powder [47] and other plant raw materials [39]. Higher values were reported for boiled $(1.69 \mathrm{~g} / \mathrm{g})[48,56]$ and washed AP $(2.24 \mathrm{~g} / \mathrm{g})$ [55]. On the other hand, lower values were found in different rice flours, full fat $(0.75 \mathrm{~g} / \mathrm{g})$ and defatted $(1.1 \mathrm{~g} / \mathrm{g})$ [39], dry-milled $(0.8 \mathrm{~g} / \mathrm{g})$, wet-milled $(0.58 \mathrm{~g} / \mathrm{g})$ and commercial $(0.5 \mathrm{~g} / \mathrm{g})$ [41]. OHC is related to the presence of lignin, its structure and surface properties, overall charge density, thickness, hydrophobic nature and size of particles [45,57]. Increase in drying temperature decreases the $\mathrm{OHC}$ value.

All values determined decreased with the decrease in APF particle size. Distinct effect of particle size on hydration capacity, oil absorption and emulsifying properties is in accordance with reported data [58]. Grinding may affect the hydration properties of DF as a result of an increase in surface area, leading to faster hydration [59]. However, it may cause alternation and collapse of the fiber matrix that traps water resulting in a water retention decrease. Both AP dehydration and dry AP grinding to fine and coarse APF in our study was obviously performed with no impact on the hydration characteristics of wet AP. Technological properties of APF confirmed its effectiveness in fortifying and development of DF-rich food products as well as in low calorie food.

\subsection{Production of Fortified Cookies with $25 \%, 50 \%$ and $75 \%$ of APF}

In order to demonstrate APF applicability in confectionery products fortification, an attempt was made to add more value to standard cookies, existing on the market for decades, by incorporating up to $75 \%$ of APF instead of wheat flour. Cookies were produced at a small-scale industrial level replacing $25 \%, 50 \%$ and $75 \%$ of soft wheat flour with both fine and coarse APF. Thermal behavior of APF was reported in our previous work. Thermal stability at up to $220^{\circ} \mathrm{C}$ was demonstrated [17]. Temperature of cookies baking $\left(175^{\circ} \mathrm{C}\right)$ was much lower.

\subsection{Functionality of Fortified Cookies}

Level of fortification of the cookies i.e., functional characteristics of fortified cookies was determined based on an increase of phytochemicals content and AO activity. Significant improvement of standard cookies functionality, achieved by delivering both fiber and AOs through the incorporation of APF, was confirmed.

\subsubsection{Content of Dietary Fibers}

Functional health-promoting cookies containing $10.1 \pm 0.9,20.6 \pm 1.7$ and $31.4 \pm 2.9 \mathrm{~g}$ DF per $100 \mathrm{~g}$ were produced when replacing wheat flour with $25 \%, 50 \%$ and $75 \%$ APF, respectively while standard cookies with wheat flour only contained $1.7 \pm 0.3 \mathrm{~g}$ DF per $100 \mathrm{~g}$. It can be concluded that the cookies produced meet the requirements for high fiber foods [60].

\subsubsection{Content of Dietary Polyphenolics (TPCs) and Flavonoids (TFCs)}

TPC and TFC, determined after production, corresponded to the percentage of APF added. Compared to the control sample, TPC was 1.1, 1.8 and 2.3 and 1.1, 1.5 and 1.9 times higher for cookies with $25 \%, 50 \%$ and $75 \%$ of coarse and fine APF, while TFC was increased 3.6-, 6.7- and 9.5- and 4.0-, 5.9and 7.6-fold, respectively (Figure 1). 

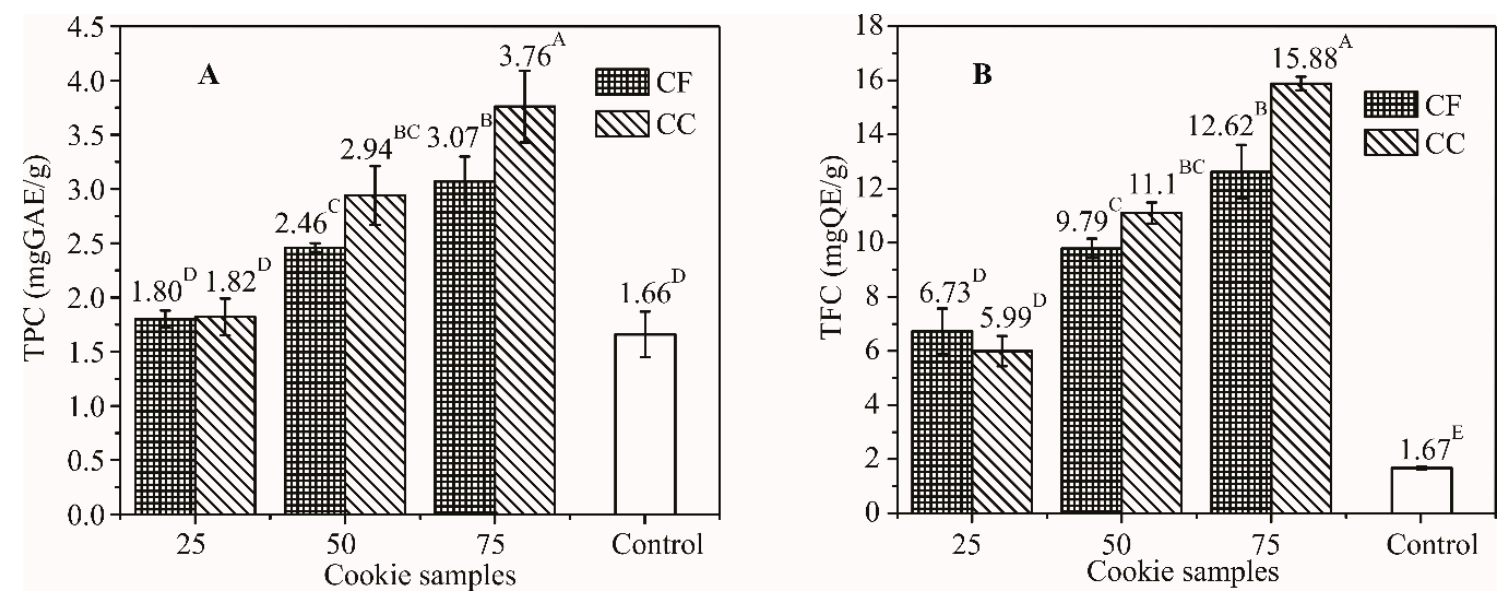

Figure 1. Increase of the total polyphenolic (TPC; A) and flavonoid content (TFC; B) of cookies in relation to the percentage of wheat flour substituted with coarse and fine APF (different superscripts indicate significant differences of means, according to Tukey's HSD (honestly significant difference) test $(p<0.05))$.

\subsubsection{Antioxidant Activity}

Radical scavenging activity towards artificial radical species DPPH and ABTS increased 3.2-, 4.0- and 5.5- and 2.9-, 4.0- and 4.5-fold, and 4.4-, 7.4- and 8.9- and 4.6-, 6.7- and 8.5-fold, respectively (Figure 2).
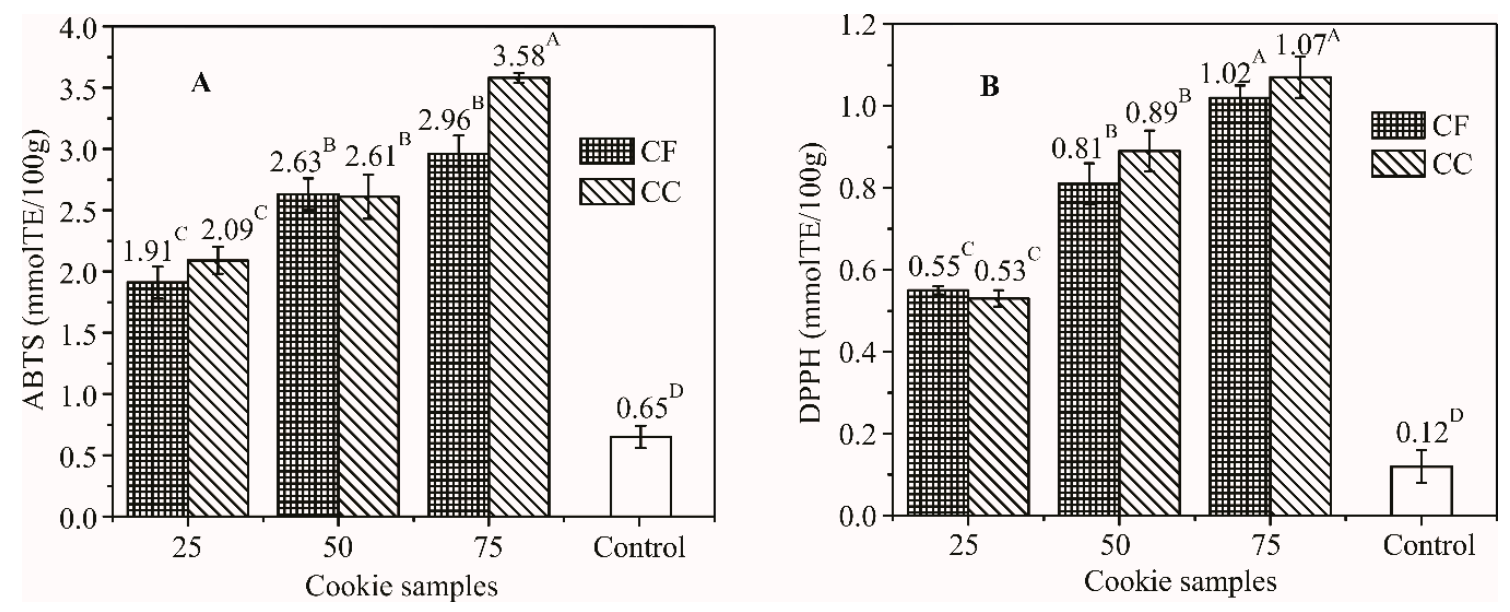

Figure 2. Increase of antioxidant (AO) activity of cookies determined by the ABTS (A) and DPPH (B) test in relation to the percentage of wheat flour substituted with coarse and fine APF (different superscripts indicate significant differences of means, according to Tukey's HSD test $(p<0.05))$.

The obtained results indicated that the substitution of wheat flour with APF significantly upgraded the content of $\mathrm{DF}$, polyphenolics and flavonoids and the $\mathrm{AO}$ activity. At the same time, gluten content was significantly decreased. It is worth noting that all parameters measured were generally higher for cookies with coarse flour. Larger particles probably enable better preservation due to lower exposure of polyphenolics to the matrix.

Previous studies aimed at determining the effect of the addition of fruit and vegetable pomace in confectionery and bakery products also showed a significant increase in AO activity [61,62]. A significant progressive increase in TPC and TFC with the increase of AP level also was reported, along with an increase in radical scavenging and reducing ability [22]. Cakes prepared with AP were reported to have higher DF and polyphenolics contents than the control product, while the antioxidant property of AP was considered to function as a natural substitute for synthetic antioxidants [63]. In the 
recent study conducted by Alongi et al. [47], it was shown that partial replacement of wheat flour in short dough biscuits with $10 \%$ and $20 \%$ of AP led to a significant reduction of glycemic index, thus representing a possible strategy for diabetes type 2 management. Cookies with high APF share could be an even more promising final product in respect to glycemic index decrease.

\subsection{Sensorial Properties of Fortified Cookies}

In several researches, bakery and confectionery products various shares of AP incorporated were assessed for sensory properties and consumer acceptance. While products with the AP share of up to $20 \%$ usually had a pleasant apple flavor and good acceptance at the consumer level $[19,50]$ - the sensory parameters more often decreased with a further increase in the AP ratio. Lower or moderate acceptability of cookies with $30 \%, 40 \%$ and $50 \%$ of AP was reported [24,25]. In concordance with previously published studies, cookies produced within the scope of this study with $25 \%$ of APF were best rated. From the obtained results (Table 2), it can be seen that in terms of overall sensory quality, the best rated cookies were CC25. They received the highest scores for all tested attributes. They were distinguished by typical appearance, corresponding texture and distinctive aroma. However, CC50 were also in the category of 'excellent quality' while all other samples had 'very good quality', including the control. Due mostly to an insufficiently baked layer in the structure of the cookies and a lack of crunchiness, CC75 received the lowest scores.

Table 2. Sensory evaluation of cookies with $25 \%, 50 \%$ and $75 \%$ of fine and coarse APF after production.

\begin{tabular}{ccccccc}
\hline & Appearance & $\begin{array}{c}\text { Structure, } \\
\text { Snap, } \\
\text { Doneness }\end{array}$ & Chewiness & Odor & Taste & Overall \\
\hline Control & $4.81 \pm 0.12^{\mathrm{a}}$ & $4.44 \pm 0.12^{\mathrm{ab}}$ & $4.16 \pm 0.23^{\mathrm{bcd}}$ & $4.66 \pm 0.44^{\mathrm{abc}}$ & $4.34 \pm 0.13^{\mathrm{abc}}$ & $4.46 \pm 0.10^{\mathrm{b}}$ \\
0-CF25 & $4.06 \pm 0.12^{\mathrm{cd}}$ & $3.94 \pm 0.18^{\mathrm{cde}}$ & $4.06 \pm 0.12^{\mathrm{cd}}$ & $4.12 \pm 0.23^{\mathrm{cd}}$ & $4.25 \pm 0.19^{\mathrm{bc}}$ & $4.10 \pm 0.08^{\mathrm{cd}}$ \\
0-CF50 & $3.84 \pm 0.13^{\mathrm{cde}}$ & $3.81 \pm 0.26^{\mathrm{de}}$ & $3.75 \pm 0.33^{\mathrm{def}}$ & $4.19 \pm 0.22^{\mathrm{cd}}$ & $4.06 \pm 0.12^{\mathrm{cd}}$ & $3.94 \pm 0.10^{\mathrm{de}}$ \\
0-CF75 & $3.59 \pm 0.13^{\text {ef }}$ & $3.50 \pm 0.23^{\text {ef }}$ & $3.34 \pm 0.13^{\text {ef }}$ & $4.44 \pm 0.32^{\mathrm{abcd}}$ & $3.63 \pm 0.44^{\mathrm{de}}$ & $3.70 \pm 0.21^{\text {ef }}$ \\
0-CC25 & $4.59 \pm 0.33^{\mathrm{ab}}$ & $4.75 \pm 0.00^{\mathrm{a}}$ & $4.75 \pm 0.35^{\mathrm{a}}$ & $4.84 \pm 0.13^{\mathrm{a}}$ & $4.84 \pm 0.19^{\mathrm{a}}$ & $4.77 \pm 0.11^{\mathrm{a}}$ \\
0-CC50 & $4.06 \pm 0.18^{\mathrm{cd}}$ & $4.66 \pm 0.13^{\mathrm{a}}$ & $4.50 \pm 0.33^{\mathrm{abc}}$ & $4.81 \pm 0.12^{\mathrm{a}}$ & $4.75 \pm 0.19^{\mathrm{ab}}$ & $4.59 \pm 0.11^{\mathrm{ab}}$ \\
0-CC75 & $3.66 \pm 0.30^{\mathrm{def}}$ & $3.94 \pm 0.18^{\mathrm{cde}}$ & $3.84 \pm 0.19^{\mathrm{de}}$ & $4.75 \pm 0.19^{\mathrm{ab}}$ & $4.13 \pm 0.40^{\mathrm{cd}}$ & $4.09 \pm 0.14^{\mathrm{d}}$ \\
\hline
\end{tabular}

The values are presented as mean $\pm \mathrm{SD}$, different superscripts within the same column indicate significant differences of means, according to Tukey's HSD test $(p<0.05)$.

The use of laboratory produced AP powder increased the ratings for fruit and baking flavor of short dough biscuits, according to Alongi et al. [47]. While finer particle size of AP performed better than larger ones when used for cakes [63], this study revealed that cookies containing coarse APF possess better sensory properties along with superior nutritional value.

No differences in panel scores were observed previously for cookies with $30 \%, 40 \%$ and $50 \%$ of AP [25]. They all had lower scores in comparison to cookies produced and tested within the scope of this study. The average score for appearance was $3.1 \pm 1.1$; flavor, $3.0 \pm 1.0$, texture, $3.1 \pm 1.1$ and overall acceptability, $3.0 \pm 1.0$ (8-point hedonic scale of $1=$ like extremely and $8=$ dislike extremely was used) [25].

\subsection{Storability of Fortified Cookies}

\subsubsection{The Effect of Storage on the Functional Properties of Fortified Cookies}

After 12 months (12 m) no statistically significant change in the content of DF was observed. The differences among fortified and standard cookies (control) in terms of polyphenolics and flavonoids content and AO activity determined by ABTS and DPPH tests were found to be greater, but with the same trend (Figure 3). 

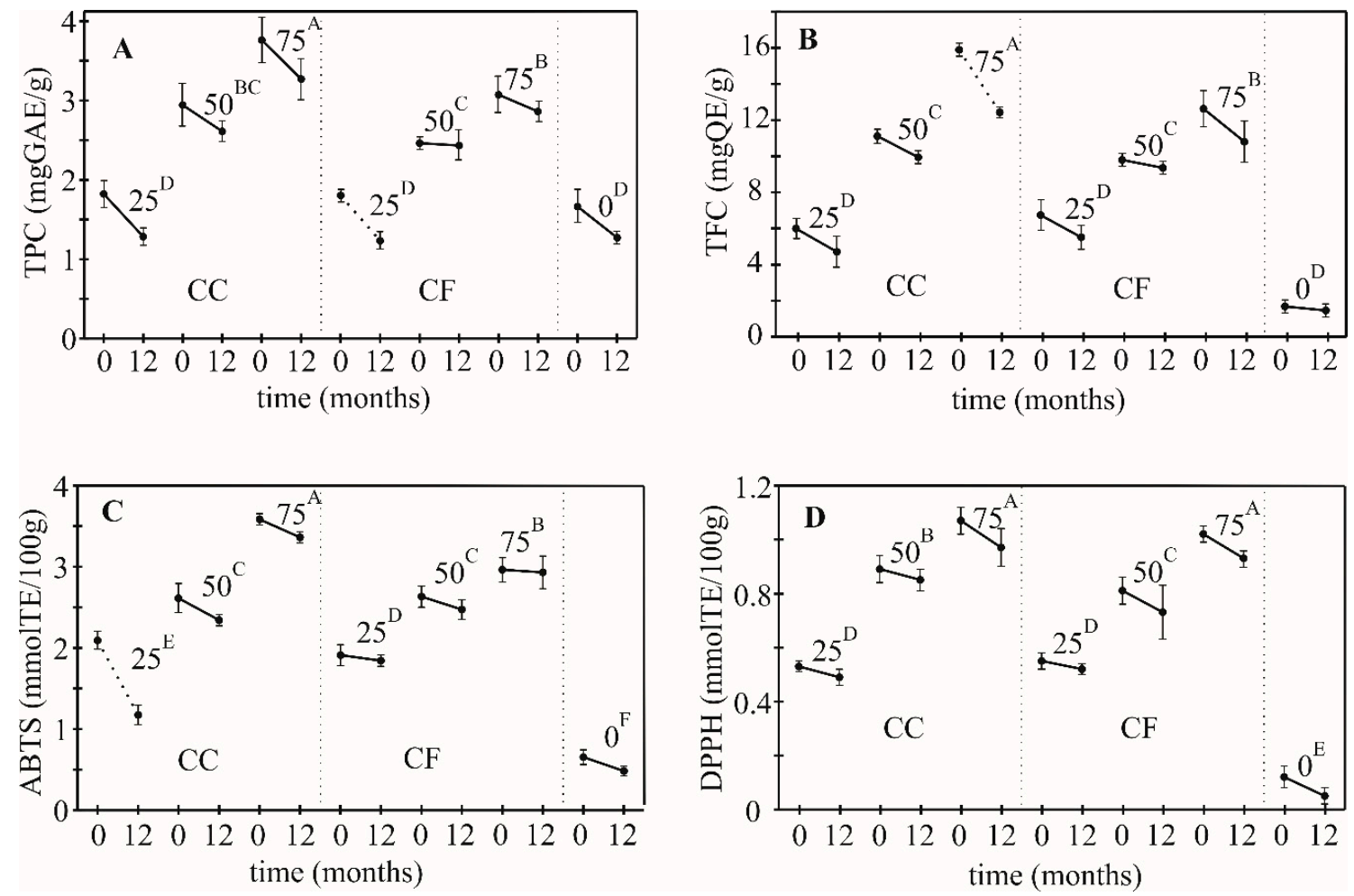

Figure 3. Decrease of TPC (A), TFC (B), scavenging of ABTS (C) and DPPH (D) test during 12 months storage of cookies ( $\mathrm{CC}$ - cookies with coarse $\mathrm{APF}, \mathrm{CF}$ - cookies with fine APF) in relation to the percentage of wheat flour substituted with APF (25\%,50\% and $75 \%$; different superscripts indicate significant differences of means, according to Tukey's HSD test $(p<0.05)$, dashed line indicates the significant drop in value after 12 months $(p<0.05))$.

Fortified cookies still have much higher values than control cookies. A decrease in the TPC value observed after storage was found significant only in the CF25 $(p<0.05)$. Values for TFCs significantly decreased in CC75 $(p<0.05)$. The DPPH values in all cookies remained unchanged after one year, while ABTS values decreased significantly only in CC25 $(p<0.05)$. Generally, the decrease was the lowest in cookies with $50 \%$ share of APF. The drop of TFC, TPC, ABTS and DPPH of CC50 $(4.5 \%, 1.2 \%, 6.1 \%$ and $9.9 \%)$ and CF50 (10.5\%, $11.2 \%, 10.3 \%$ and $4.5 \%)$ was significantly lower than in control $(12.6 \%, 23.5 \%$, $26.2 \%$ and $58.3 \%)$.

\subsubsection{The Effect of Storage on the Sensorial Properties of Fortified Cookies}

With the aim to get an insight into changes in sensorial properties of cookies, the cookies were also assessed after 12 months, using the same method. After one year of storage, a slight decline in scores was noticed, but all samples remained in the initial quality category. The decrease of grades was due to expected modifications during long storage, such as color changes or loss of aroma and crunchiness, and not by the addition of APF (Table 3). Higher overall sensorial quality of CC25 and CC50 compared to the control in both testing periods indicates that there is a justification of the production of this type of functional cookies and that they have good prospects among consumers. In previous studies, AP powder used to fortify cookies also showed a positive influence on the cookies' sensory attributes during storage. Cookies with $10 \%$ of AP maintained better sensory attributes and better storage stability compared to control cookies [36]. Results presented here support the hypothesis presented by Sahni and Shere [36] that fortified cookies might demand comparatively simple packaging. 
Table 3. Sensory evaluation of cookies with $25 \%, 50 \%$ and $75 \%$ of fine and coarse APF after 12 months of storage.

\begin{tabular}{ccccccc}
\hline & Appearance & $\begin{array}{c}\text { Structure, } \\
\text { Snap, } \\
\text { Doneness }\end{array}$ & Chewiness & Odor & Taste & Overall \\
& & & & & \\
\hline 12-control & $4.81 \pm 0.12^{\mathrm{a}}$ & $4.41 \pm 0.30^{\mathrm{abc}}$ & $4.13 \pm 0.23^{\mathrm{bcd}}$ & $4.50 \pm 0.40^{\mathrm{abcd}}$ & $4.25 \pm 0.30^{\mathrm{bc}}$ & $4.39 \pm 0.18^{\mathrm{bc}}$ \\
12 -CF25 & $4.22 \pm 0.21^{\mathrm{bc}}$ & $4.03 \pm 0.36^{\mathrm{bcd}}$ & $3.94 \pm 0.12^{\mathrm{cd}}$ & $4.13 \pm 0.27^{\mathrm{cd}}$ & $4.13 \pm 0.13^{\mathrm{cd}}$ & $4.08 \pm 0.12^{\mathrm{d}}$ \\
12 -CF50 & $3.91 \pm 0.19^{\mathrm{cde}}$ & $3.72 \pm 0.41^{\mathrm{de}}$ & $3.34 \pm 0.27^{\mathrm{ef}}$ & $4.22 \pm 0.21^{\mathrm{bcd}}$ & $3.63 \pm 0.30^{\mathrm{de}}$ & $3.75 \pm 0.18^{\mathrm{e}}$ \\
12 -CF75 & $3.34 \pm 0.30^{\mathrm{f}}$ & $3.22 \pm 0.39^{\mathrm{f}}$ & $3.19 \pm 0.32^{\mathrm{f}}$ & $4.06 \pm 0.44^{\mathrm{d}}$ & $3.25 \pm 0.52^{\mathrm{e}}$ & $3.41 \pm 0.26^{\mathrm{f}}$ \\
12 -CC25 & $4.66 \pm 0.30^{\mathrm{a}}$ & $4.75 \pm 0.19^{\mathrm{a}}$ & $4.66 \pm 0.44^{\mathrm{ab}}$ & $4.81 \pm 0.22^{\mathrm{a}}$ & $4.59 \pm 0.30^{\mathrm{abc}}$ & $4.69 \pm 0.10^{\mathrm{ab}}$ \\
$12-$ CC50 & $4.09 \pm 0.13^{\mathrm{c}}$ & $4.50 \pm 0.19^{\mathrm{ab}}$ & $4.44 \pm 0.55^{\mathrm{abc}}$ & $4.81 \pm 0.22^{\mathrm{a}}$ & $4.72 \pm 0.25^{\mathrm{ab}}$ & $4.54 \pm 0.17^{\mathrm{ab}}$ \\
12 -CC75 & $3.50 \pm 0.19^{\text {ef }}$ & $3.81 \pm 0.26^{\mathrm{de}}$ & $3.72 \pm 0.21^{\mathrm{def}}$ & $4.66 \pm 0.13^{\mathrm{abc}}$ & $3.69 \pm 0.12^{\mathrm{de}}$ & $3.88 \pm 0.13^{\mathrm{de}}$ \\
\hline
\end{tabular}

The values are presented as mean $\pm \mathrm{SD}$, different superscripts within the same column indicate significant differences of means, according to Tukey's HSD test $(p<0.05)$.

The lowest changes of both sensorial and nutritional properties that occur in CC50 during storage favor the ratio of $50 \%$ of coarse flour as optimal for industrial production of fortified cookies.

The cookies containing coarse APF showed better sensory properties than those with fine APF, both at the beginning and at the end of the storage period. Although CC25 received a better score immediately after production, the decrease in $\mathrm{AO}$ activity and polyphenolic content during storage was the lowest for CC50. In this sense, CC50, as the choice superior to CC25 in terms of phytochemicals content and $\mathrm{AO}$ activity preservation during storage, could also be considered for consumer preferences testing using the hedonic scale.

\subsection{Estimation of the Optimal Share and Particle Size of APF}

To obtain a more comprehensive comparison between the produced cookies and to achieve as reliable a recommendation as possible regarding which ratio of APF to use in cookie fortification, functional and sensory characteristics were subjected to multivariate analysis by principal component analysis (PCA) followed by a Varimax rotation. Therefore, the following variables: TPC, TFC, ABTS, $\mathrm{DPPH}$, appearance, structure, chewiness, odor, taste and overall quality were considered. The results showed that the first two principal components (PC) explain $94.86 \%$ of the total variance of initial data (PC1 explains 47.79\%, and PC2 explains 47.07\%). Projection of the initial variables in the PC1 vs. PC2 plane is shown in Figure 4A.

It can be seen that the PC1 is strongly related to variables associated with polyphenolic (TPC) and flavonoid (TFC) content and scavenging capacity (ABTS and DPPH). In the case of PC2, the most important variables are related to the sensory perception: structure, chewiness, odor, taste and overall quality. Thus, one can interpret the two first components, as follows: PC1—physicochemical characteristics (antioxidative property) and PC2 - sensory characteristics of samples.

Samples at the beginning (prefix "0-“) and after 12 months (prefix "12-“) in the PC1 vs. PC2 plane are shown in Figure 4B. The samples that are close to each other have similar properties, overall, and samples that are far apart are very different. To examine the influence of storage time on the change in functional and sensory characteristics of the samples, the distance between the points representing the sample at the beginning and after 12 months were observed. A larger distance indicates more intensive changes in the analyzed characteristics of sample over the observed time period. It can be seen that CC50 and CF25 changed the least with time in terms of functional and sensory properties. PCA results unequivocally confirm the better performance of coarse APF in cookie formulations. It allows CC50 to be reliably recommended for further production. Hence, consumers' acceptance of cookies with $50 \%$ of coarse flour was further tested by hedonic tests. 

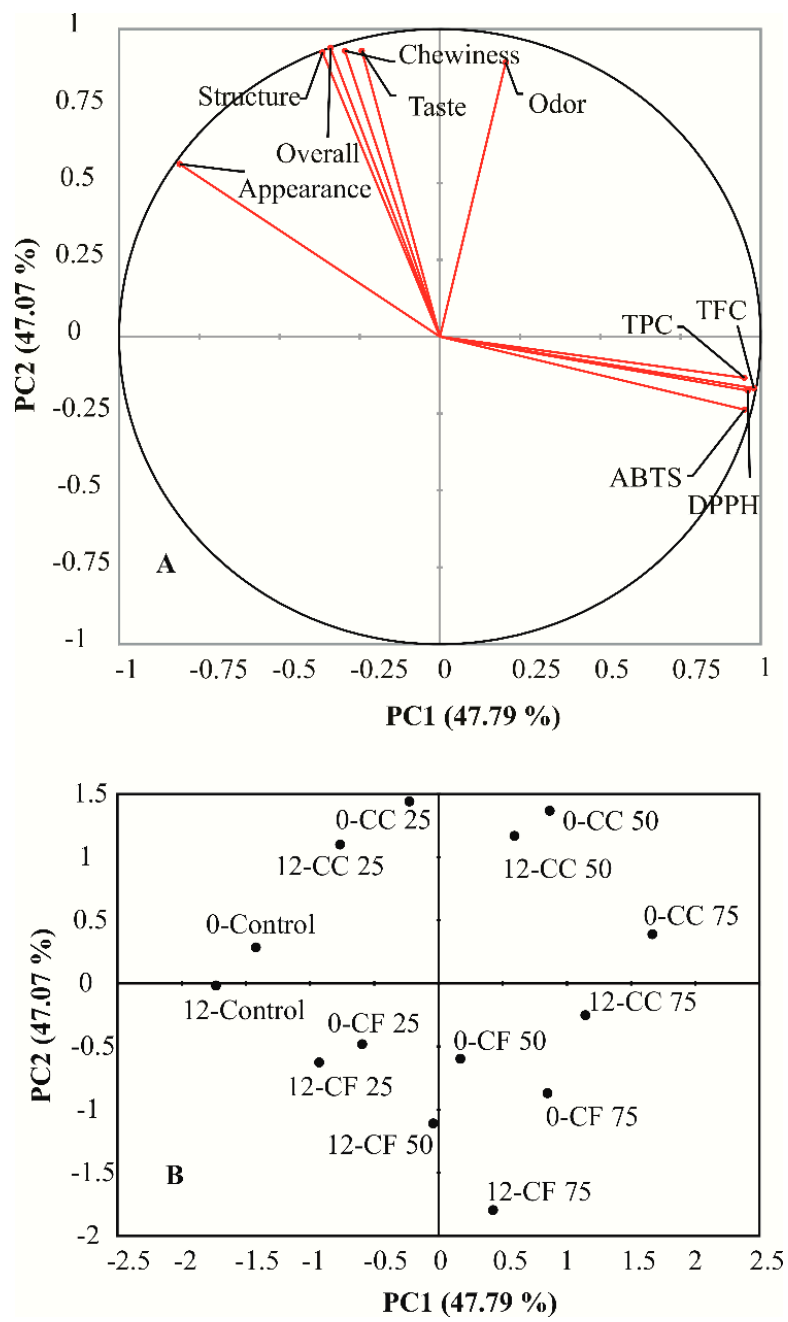

Figure 4. Principal component analysis (PCA) followed by Varimax rotation of samples (PC1 vs. PC2 plane): (A) correlation circle of variables and (B) samples in factor plane (samples at the beginning-prefix “0-“ and after 12 months-prefix “12-“).

\subsection{Consumer Acceptability of Cookies with $50 \%$ of Coarse APF}

The results of the mean drop analysis for CC50 are shown in Figure 5. A point in the plot that shows a statistically significant mean drop and the percentage of consumers above the cut-off point is a cause for concern and suggests that the product be modified in the appropriate direction [64]. Two sufficiently large consumer groups $(\geq 20 \%)$ with significant mean drops $(p<0.05)$ were identified for the tested product. One felt the product was 'not sweet enough' (32.2\% of respondents), and the other that product had 'too weak apple odor' (41.7\%). Average hedonic scores for the latter group were $4.3 \pm 1.9$ for 'odor acceptance' and $5.9 \pm 1.5$ for 'overall acceptance', i.e., more or less within the range of 'neither like nor dislike' category. The 'apple-odor' feature could be enhanced and intensified by proper selection of apple cultivars to be used in the production of this kind of product [65]. This property can also be affected by the degree of ripeness of the used fruits [66].

Looking at the total number of respondents, 'overall acceptance', 'texture acceptance' and 'flavor acceptance' were scored with the average hedonic scores above $6(6.2 \pm 1.8)$, indicating that the tested respondents liked the product. 


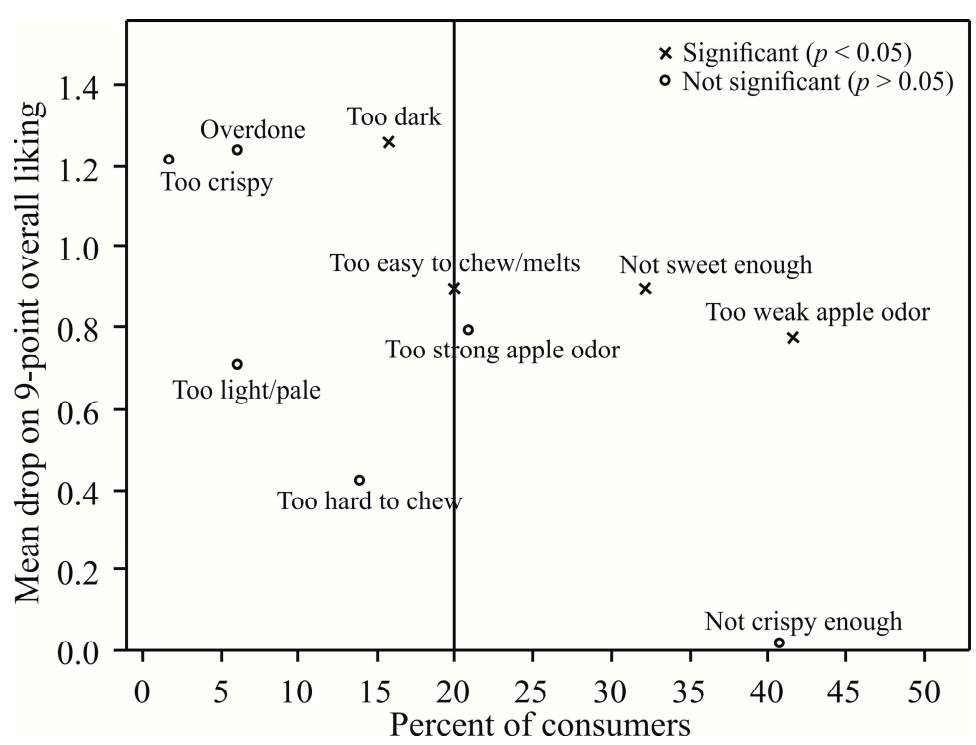

Figure 5. Mean drop analysis for the cookies with 50\% of coarse APF ( $n=115$ respondents).

\section{Conclusions}

This study showed that APF can be recommended as a flour fortifier and applied as an ingredient of functional products. Applicability of APF in industrial production of fortified cookies was demonstrated. Coarse APF performed better, both regarding functional properties and sensorial attributes in comparison to fine APF. Cookies fortified with coarse APF possessed a higher content of health promoting components in comparison to control samples, while its decrease during storage was lower. According to the scoring method, APF can be incorporated up to the level of $50 \%$ in cookie recipes, without significantly affecting sensorial properties. Consumers' evaluation using a hedonic test also confirmed that replacement of up to $50 \%$ of wheat flour with coarse APF at industrial-scale production of cookies was possible, without compromising products acceptability. APF's potential in bridging DF and AOs gaps, while also conferring a pleasant apple taste and crunchy texture that lasted throughout 12 months storage, was shown.

\section{Patents}

Zlatanović, S., Gorjanović, S., Ostojić, S., Micić, D., Pastor, F., Kalušević, A. and Laličić-Petronijević, J. PCT/RS2019/000019, 2019. International Patent Application.

Author Contributions: Initiated and designed the research concept, S.G.; Wrote the manuscript, S.G., S.Z., J.L.-P. and A.K.; Organized and performed industrial production of apple pomace flour, S.G. and S.Z.; Designed and organized industrial production of cookies, J.L.-P. and A.K.; Performed all the experimental work required for this study, A.K., S.Z. and S.G.; Designed and conducted sensory analysis, J.L.-P. and N.T.; Performed the statistical analysis of results, D.M. and N.T.; Contributed to analysis of results, S.O.

Funding: This work was supported by the Ministry of Education, Science and Technological Development of Republic of Serbia, Grants 43010, 31055 and 31093.

Acknowledgments: The contributions of juice producer Fruvita, Ltd., Smederevo, Serbia for apple pomace supplying, Drier, Ltd., Belgrade, Serbia and Sunny delight, Ltd., Pančevo, Serbia for technical support and Gold, Kusadak, Serbia for industrial production of cookies are gratefully acknowledged. Also, we gratefully acknowledge the financial support of the Innovation Fund of the Republic of Serbia, TTF Grant No. 1076.

Conflicts of Interest: The authors declare no conflict of interest.

\section{References}

1. Skinner, R.C.; Gigliotti, J.C.; Ku, K.-M.M.; Tou, J.C. A comprehensive analysis of the composition, health benefits, and safety of apple pomace. Nutr. Rev. 2018, 76, 893-909. [CrossRef] 
2. Masoodi, F.A.; Sharma, B.; Chauhan, G.S. Use of apple pomace as a source of dietary fiber in cakes. Plant Foods Hum. Nutr. 2002, 57, 121-128. [CrossRef]

3. Wolfe, K.L.; Liu, R.H. Apple Peels as a Value-Added Food Ingredient. J. Agric. Food Chem. 2003, 51, 1676-1683. [CrossRef]

4. Sun, L.; Sun, J.; Meng, Y.; Yang, X.; Guo, Y. Purification, Characterization, Antioxidant and Antitumour Activities of Polysaccharides from Apple Peel Pomace Obtained by Pre-pressing Separation. Int. J. Food Eng. 2017, 13, 14. [CrossRef]

5. Yang, X.; Yang, S.; Guo, Y.; Jiao, Y.; Zhao, Y. Compositional characterisation of soluble apple polysaccharides, and their antioxidant and hepatoprotective effects on acute CCl4-caused liver damage in mice. Food Chem. 2013, 138, 1256-1264. [CrossRef]

6. Cao, X.; Wang, C.; Pei, H.; Sun, B. Separation and identification of polyphenols in apple pomace by high-speed counter-current chromatography and high-performance liquid chromatography coupled with mass spectrometry. J. Chromatogr. A 2009, 1216, 4268-4274. [CrossRef]

7. Ćetković, G.; Čanadanović-Brunet, J.; Djilas, S.; Savatović, S.; Mandić, A.; Tumbas, V. Assessment of polyphenolic content and in vitro antiradical characteristics of apple pomace. Food Chem. 2008, 109, 340-347. [CrossRef]

8. Rana, S.; Rana, A.; Gulati, A.; Bhushan, S. RP-HPLC-DAD Determination of Phenolics in Industrial Apple Pomace. Food Anal. Methods 2014, 7, 1424-1432. [CrossRef]

9. Sánchez-Rabaneda, F.; Jáuregui, O.; Lamuela-Raventós, R.M.; Viladomat, F.; Bastida, J.; Codina, C. Qualitative analysis of phenolic compounds in apple pomace using liquid chromatography coupled to mass spectrometry in tandem mode. Rapid Commun. Mass Spectrom. 2004, 18, 553-563. [CrossRef]

10. Reis, S.F.; Rai, D.K.; Abu-Ghannam, N. Apple pomace as a potential ingredient for the development of new functional foods. Int. J. Food Sci. Technol. 2014, 49, 1743-1750. [CrossRef]

11. Rana, S.; Bhushan, S. Apple phenolics as nutraceuticals: Assessment, analysis and application. J. Food Sci. Technol. 2016, 53, 1727-1738. [CrossRef] [PubMed]

12. Ratti, C. Hot air and freeze-drying of high-value foods: A review. J. Food Eng. 2001, 49, 311-319. [CrossRef]

13. Tambunan, A.H.; Yudistira; Kisdiyani; Hernani. Freeze drying characteristics of medicinal herbs. Dry. Technol. 2001, 19, 325-331. [CrossRef]

14. Tseng, A.; Zhao, Y. Effect of Different Drying Methods and Storage Time on the Retention of Bioactive Compounds and Antibacterial Activity of Wine Grape Pomace (Pinot Noir and Merlot). J. Food Sci. 2012, 77, H192-H201. [CrossRef]

15. Veselinović, N.; Veselinović, M. Solar and Electric Energy Dryers. U.S. 2010/0223807 A1 9 September 2010.

16. Zlatanović, S.; Gorjanović, S.; Ostojić, S.; Micić, D.; Pastor, F.; Kalušević, A.; Laličić-Petronijević, J. Method for Producing Gluten-Free Flour Made of Apple Pomace. RS P20180918 PCT/RS2019/000019 3 August 2019. International Patent Application 2019.

17. Zlatanović, S.; Ostojić, S.; Micić, D.; Rankov, S.; Dodevska, M.; Vukosavljević, P.; Gorjanović, S. Thermal behaviour and degradation kinetics of apple pomace flours. Thermochim. Acta 2019, 673, 17-25. [CrossRef]

18. Rupasinghe, H.P.V.; Wang, L.; Huber, G.M.; Pitts, N.L. Effect of baking on dietary fibre and phenolics of muffins incorporated with apple skin powder. Food Chem. 2008, 107, 1217-1224. [CrossRef]

19. Sudha, M.L.; Baskaran, V.; Leelavathi, K. Apple pomace as a source of dietary fiber and polyphenols and its effect on the rheological characteristics and cake making. Food Chem. 2007, 104, 686-692. [CrossRef]

20. Masoodi, F.A.; Chauhan, G.S. Use of apple pomace as a source of dietary fiber in wheat bread. J. Food Process. Preserv. 1998, 22, 255-263. [CrossRef]

21. Jung, J.; Cavender, G.; Zhao, Y. Impingement drying for preparing dried apple pomace flour and its fortification in bakery and meat products. J. Food Sci. Technol. 2015, 52, 5568-5578. [CrossRef]

22. Mir, S.A.; Bosco, S.J.D.; Shah, M.A.; Santhalakshmy, S.; Mir, M.M. Effect of apple pomace on quality characteristics of brown rice based cracker. J. Saudi Soc. Agric. Sci. 2017, 16, 25-32. [CrossRef]

23. Kaushal, N.; Joshi, V. Preparation and evaluation of apple pomace based cookies. Indian Food Pack 1995, 49, $17-24$.

24. Saeed, M.; Inam-Ur-Raheem, M.; Shakeel, A.; Wasim Aslam, H.K.; Siddique Raza, M.; Razzaq, Z.; Muhammad, R.S.; Shoaib, M. Effect of water chest nut and apple pomace powder on the quality parameters of cookies. J. Glob. Innov. Agric. Soc. Sci. 2015, 3, 142-145. 
25. Carson, K.J.; Collins, J.L.; Penfield, M.P. Unrefined, Dried Apple Pomace as a Potential Food Ingredient. J. Food Sci. 1994, 59, 1213-1215. [CrossRef]

26. Jacobs, P.J.; Hemdane, S.; Dornez, E.; Delcour, J.A.; Courtin, C.M. Study of hydration properties of wheat bran as a function of particle size. Food Chem. 2015, 179, 296-304. [CrossRef]

27. Elkhalifa, A.E.O.; Schiffler, B.; Bernhardt, R. Effect of fermentation on the functional properties of sorghum flour. Food Chem. 2005, 92, 1-5. [CrossRef]

28. Rana, S.; Gupta, S.; Rana, A.; Bhushan, S. Functional properties, phenolic constituents and antioxidant potential of industrial apple pomace for utilization as active food ingredient. Food Sci. Hum. Wellness 2015, 4, 180-187. [CrossRef]

29. Robertson, J.A.; de Monredon, F.D.; Dysseler, P.; Guillon, F.; Amado, R.; Thibault, J.-F. Hydration Properties of Dietary Fibre and Resistant Starch: A European Collaborative Study. LWT Food Sci. Technol. 2000, 33, 72-79. [CrossRef]

30. AOAC. Total dietary fiber in foods: Enzymatic-gravimetric method. In Official Methods of Analysis, Method 985.29; AOAC International: Arlington, VA, USA, 1990.

31. Singleton, V.L.; Rossi, J.A. Colorimetry of total phenolics with phosphomolybdic-phosphotungstic acid reagents. Am. J. Enol. Vitic. 1965, 16, 144-158.

32. Zhishen, J.; Mengcheng, T.; Jianming, W. The determination of flavonoid contents in mulberry and their scavenging effects on superoxide radicals. Food Chem. 1999, 64, 555-559. [CrossRef]

33. Kaneda, H.; Kobayashi, N.; Furusho, S.; Sahara, H.; Koshino, S. Reducing activity and flavor stability of beer. Tech. Q. Master Brew. Assoc. Am. 1995, 32, 90-94.

34. Re, R.; Pellegrini, N.; Proteggente, A.; Pannala, A.; Yang, M.; Rice-Evans, C. Antioxidant activity applying an improved ABTS radical cation decolorization assay. Free Radic. Biol. Med. 1999, 26, 1231-1237. [CrossRef]

35. Schraidt, M. Appendix L: Penalty analysis or mean drop analysis. In ASTM Manual Series: MNL 63-Just-About-Right (JAR) Scales: Design, Usage, Benefits and Risks; Rothman, L., Parker, M.J., Eds.; ASTM International-American Society for Testing and Materials: Bridgeport, NJ, USA, 2009; pp. 50-53.

36. Sahni, P.; Shere, D. Effect of Different Packaging Materials on Sensory Attributes of Fibre Rich Cookies during Storage. Int. J. Pure Appl. Biosci. 2017, 5, 265-272. [CrossRef]

37. Jakubczyka, E.; Gondeka, E.; Tamborb, K. Characteristics of selected functional properties of apple powders obtained by the foam-mat drying method. In Proceedings of the Food Process Engineering in a Changing World, Athens, Greece, 22-26 May 2011; Taoukis, P.S., Stoforos, N.G., Karathanos, V.T., Saravacos, G.D., Eds.; Cosmosware: Athens, Greece, 2011; pp. 1385-1386.

38. Oyeyinka, S.A.; Oyeyinka, A.T.; Opaleke, D.O.; Karim, O.R.; Kolawole, F.L.; Ogunlakin, G.O.; Olayiwola, O.H. Cake production from wheat (triticum aestivum) and cowpea (vigna unguiculata) flours using date fruit as a sweetener. Ann. Food Sci. Technol. 2014, 15, 20-28.

39. Joshi, A.U.; Liu, C.; Sathe, S.K. Functional properties of select seed flours. LWT Food Sci. Technol. 2015, 60, 325-331. [CrossRef]

40. Kang, H.-M.; Lee, J.-H.; Kim, R.-H.; Yun, J.-H.; Chun, B.-S. Characterization of Wheat Flour Treated by Supercritical Carbon Dioxide. APCBEE Procedia 2012, 2, 12-16. [CrossRef]

41. Rosniyana, A.; Hazila, K.K.; Norin, S.; Abdullah, S. Characteristics of local rice flour (MR 220) produced by wet and dry milling methods. J. Trop. Agric. Fd. Sc 2016, 44, 147-155.

42. Charrondiere, U.R.; Haytowitz, D.; Stadlmayr, B. INFOODS: FAO/INFOODS Density Database—Version 2.0; FAO: Rome, Italy, 2012.

43. Oladapo, A.; Adepeju, A.; Akinyele, A.; Adepeju, D. The Proximate, Functional and Anti-Nutritional Properties of Three Selected Varieties of Maize (Yellow, White and Pop Corn) Flour. Int. J. Sci. Sci. 2017, 1, 23-26.

44. Elleuch, M.; Bedigian, D.; Roiseux, O.; Besbes, S.; Blecker, C.; Attia, H. Dietary fibre and fibre-rich by-products of food processing: Characterisation, technological functionality and commercial applications: A review. Food Chem. 2011, 124, 411-421. [CrossRef]

45. Figuerola, F.; Hurtado, M.L.; Estévez, A.M.; Chiffelle, I.; Asenjo, F. Fibre concentrates from apple pomace and citrus peel as potential fibre sources for food enrichment. Food Chem. 2005, 91, 395-401. [CrossRef]

46. Ktenioudaki, A.; O'Shea, N.; Gallagher, E. Rheological properties of wheat dough supplemented with functional by-products of food processing: Brewer's spent grain and apple pomace. J. Food Eng. 2013, 116, 362-368. [CrossRef] 
47. Alongi, M.; Melchior, S.; Anese, M. Reducing the glycemic index of short dough biscuits by using apple pomace as a functional ingredient. LWT 2019, 100, 300-305. [CrossRef]

48. Cerda-Tapia, A.; Pérez-Chabela, M.L.; Pérez-Álvarez, J.Á.; Fernández-López, J.; Viuda-Martos, M. Valorization of Pomace Powder Obtained from Native Mexican Apple (Malus domestica var. rayada): Chemical, Techno-functional and Antioxidant Properties. Plant Foods Hum. Nutr. 2015, 70, 310-316. [CrossRef] [PubMed]

49. Bushuk, W.; Békés, F. Contribution of protein to flour quality. In Novel Raw Materials, Technologies and Products-New Challenge for the Quality Control; Salgo, A., Tomoskozi, S., Lasztity, R., Eds.; International Association for Cereal Science and Technology (ICC): Budapest, Hungary, 2002; pp. 14-19.

50. Kohajdová, Z.; Karovičová, J.; Jurasová, M.; Kukurová, K. Effect of the addition of commercial apple fibre powder on the baking and sensory properties of cookies. Acta Chim. Slovaca 2011, 4, 88-97.

51. Belorio, M.; Sahagún, M.; Gómez, M. Influence of Flour Particle Size Distribution on the Quality of Maize Gluten-Free Cookies. Foods 2019, 8, 83. [CrossRef] [PubMed]

52. Chen, H.; Rubenthaler, G.L.; Leung, H.K.; Baranowski, J.D. Chemical, Physical, and Baking Properties of Apple Fiber Compared with Wheat and Oat Bran. Cereal Chem. 1988, 65, 244-247.

53. Wang, X.; Kristo, E.; LaPointe, G. The effect of apple pomace on the texture, rheology and microstructure of set type yogurt. Food Hydrocoll. 2019, 91, 83-91. [CrossRef]

54. Dhingra, D.; Michael, M.; Rajput, H.; Patil, R.T. Dietary fibre in foods: A review. J. Food Sci. Technol. 2012, 49, 255-266. [CrossRef]

55. Sahni, P.; Shere, D. Comparative Evaluation of Physico-chemical and Functional Properties of Apple, Carrot and Beetroot Pomace Powders. Int. J. Food Ferment. Technol. 2017, 7, 317-323.

56. Rabetafika, H.N.; Bchir, B.; Aguedo, M.; Paquot, M.; Blecker, C. Effects of Processing on the Compositions and Physicochemical Properties of Fibre Concentrate from Cooked Fruit Pomaces. Food Bioprocess Technol. 2014, 7, 749-760. [CrossRef]

57. Garau, M.C.; Simal, S.; Rosselló, C.; Femenia, A. Effect of air-drying temperature on physico-chemical properties of dietary fibre and antioxidant capacity of orange (Citrus aurantium v. Canoneta) by-products. Food Chem. 2007, 104, 1014-1024. [CrossRef]

58. Grover, S.S.; Chauhan, G.S.; Masoodi, F.A. Effect of Particle Size on Surface Properties of Apple Pomace. Int. J. Food Prop. 2003, 6, 1-7. [CrossRef]

59. Sangnark, A.; Noomhorm, A. Effect of particle sizes on functional properties of dietary fibre prepared from sugarcane bagasse. Food Chem. 2003, 80, 221-229. [CrossRef]

60. Agostoni, C.; Bresson, J.-L.; Fairweather-Tait, S.; Flynn, A.; Golly, I.; Korhonen, H.; Lagiou, P.; Løvik, M.; Marchelli, R.; Martin, A.; et al. Scientific Opinion on Dietary Reference Values for carbohydrates and dietary fibre. EFSA J. 2010, 8, 1462.

61. Ajila, C.M.; Leelavathi, K.; Prasada Rao, U.J.S. Improvement of dietary fiber content and antioxidant properties in soft dough biscuits with the incorporation of mango peel powder. J. Cereal Sci. 2008, 48, 319-326. [CrossRef]

62. Tańska, M.; Roszkowska, B.; Czaplicki, S.; Borowska, E.J.; Bojarska, J.; Dąbrowska, A. Effect of Fruit Pomace Addition on Shortbread Cookies to Improve Their Physical and Nutritional Values. Plant Foods Hum. Nutr. 2016, 71, 307-313. [CrossRef] [PubMed]

63. Sudha, M.L. Apple Pomace (By-Product of Fruit Juice Industry) as a Flour Fortification Strategy. Flour Breads Their Fortif. Heal. Dis. Prev. 2011, 395-405.

64. Lawless, H.T.; Heymann, H. Introduction. In Sensory Evaluation of Food; Springer: New York, NY, USA, 2010; pp. 1-18.

65. Espino-Díaz, M.; Sepúlveda, D.R.; González-Aguilar, G.; Olivas, G.I. Biochemistry of apple aroma: A review. Food Technol. Biotechnol. 2016, 54, 375-397. [CrossRef]

66. Bangerth, F.K.; Song, J.; Streif, J. Physiological Impacts of Fruit Ripening and Storage Conditions on Aroma Volatile Formation in Apple and Strawberry Fruit: A Review. HortScience 2012, 47, 4-10. [CrossRef]

(C) 2019 by the authors. Licensee MDPI, Basel, Switzerland. This article is an open access article distributed under the terms and conditions of the Creative Commons Attribution (CC BY) license (http://creativecommons.org/licenses/by/4.0/). 